\title{
The effect of static and dynamic eccentricities on the performance of flux reversal permanent magnet machine
}

\author{
Ahlam Luaibi Shuraiji \\ Electromechanical Engineering Department, University of Technology, Iraq
}

\begin{tabular}{l}
\hline \hline Article Info \\
\hline Article history: \\
Received Aug 9, 2019 \\
Revised Oct 9, 2019 \\
Accepted Feb 7, 2020 \\
\hline
\end{tabular}

Keywords:

Dynamic eccentricity

Flux reversal permanent magnet machine

Static eccentricity

\begin{abstract}
This study investigates the effect of static and dynamic eccentricities on the performances of flux reversal permanent magnet (FRPM) machine with even rotor pole number, i.e. FRPM machine with 12/10 stator/rotor combination. No-load and load performances of the machine are investigated under three rotor operating conditions including centricity, static eccentricity and dynamic eccentricity. The investigation has been carried out using 2D-FEA. It has been revealed that the 12/10 FRPM machine under normal operating condition has no unbalanced magnetic force, due to the even pole number of the rotor. On the other hand, such undesirable feature would be presented in the 12/10 FRPM machine as a result of the existing of static and dynamic eccentricities. Both static and dynamic eccentric machines exhibit unbalanced three-phase flux linkage as well as back-EMF. Moreover, three operating conditions of the investigated machine have the same fundamental cogging torque harmonic. However, low order harmonics are existed in the static and dynamic centric machines and are not found in the centric machine. Furthermore, about $16 \%$ less torque ripple delivered by the centric machine compared with both static and dynamic counterparts.
\end{abstract}

This is an open access article under the $\underline{C C B Y-S A}$ license.

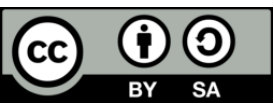

\section{Corresponding Author:}

Ahlam Luaibi Shuraiji,

Electromechanical Engineering Department,

University of Technology,

Baghdad, Iraq.

Email: ahlamly2009@yahoo.com

\section{INTRODUCTION}

Stator permanent magnet (SPM) machines have received many attentions, since the considerable achievement on the permanent magnet materials [1-5]. The idea of such machines was first introduced by Rauch and Johnson [6]. The SPM machines are generally classified to three types, which are doubly salient permanent magnet (DSPM) machines, flux reversal permanent magnet (FRPM) machines and switch flux permanent magnet (SFPM) machines. Having both exciting sources (the copper and the permanent magnet) on the stator may be considered as the main distinguished feature of such machines [7-10]. Due to this feature, the SPM machines possess the advantages of simple, passive and light rotor structure. Therefore, these topologies cooperate the features of reluctance and permanent magnet machines. The concept of the FRPM machine was presented in [11]. The machine was designed as a single-phase generator. It was concluded that the machine has the advantages of uncomplicated and strong rotor structure with small inertia, high speed ability and fault tolerance, while [12] discussed multiphase FRPM machines in which 3-phase FRPM machine was designed and analyzed by 2D-finite element analysis (FEA). It was confirmed that such machine is suitable for high as well as low speed applications and its simple structure and consequently low manufacturing coast make the FRPM machine a good candidate for many applications. Moreover, three 
phase FRPM generator was designed for automotive sector in [13]. It was delivered that the generator has low transient time and almost constant output voltage with fast speed change. Furthermore, [14] proposed rotor poles pairing technique to reduce cogging torque of the FRPM machine. To minimize the flux-leakage on the rotor poles of the FRPM machine, [15] placed flux barrier on the edges of the rotor poles, while [16] introduced a new structure of the PM for the FRPM machine known as inset FRPM machine where the PM is placed in parallel on the stator of the FRPM machine, to enhance the performance of the conventional corresponding. It was stated that the inset FRPM topology shows a better performance compared to the existing counterpart. In addition, the FRPM and DSPM machines were compared in terms of power density in [17]. It was delivered that the higher power density was obtained by the FRPM machine compared to the DSPM counterparts. Additionally, FRPM machine with full pitch winding was introduced in [18], to enhance the machine power density. Besides, d-q equivalent circuit of the FRPM with full pitch winding and concentrated winding were driven in [19]. Moreover, [20] anlysied and compared the perfromances of FRPM machine with two PM arrangments, i.e. NS-NS and NS-SN. It was shown that the NS-SN arrangement had higher speed and torque than that of the NS-NS.

Like other PM machines, FRPM machines will experience eccentricity in which both stator and rotor centers are not coincided, due to the manufacturing imperfection. It should be pointed out that the eccentricity is classified into static and dynamic eccentricities [21-24]. In static eccentricity the rotor moves around its own center and minimum air-gap between the stator and the rotor is stationary. In contrast, in dynamic eccentricity the minimum air-gap between the stator and the rotor rotates around the stator center, while the rotor revolves around its own center. The exciting of the eccentricity is negatively affecting the performances of PM machines, since it leads to unbalanced magnetic force, which results in noise and vibration. The behaviors of the rotor PM and the SFPM machines have been intensely investigated under the rotor eccentricity condition. However, the impact of the rotor eccentricity on the performances of the FRPM machine has not been reported yet. Thereby, in this study the effect of the rotor eccentricities on the performance of such machine will be comprehensively investigated. It is worth mentioning that 2D-FEA is utilized to design and analyze the understudying machine.

\section{MACHINE DESCRIPTION}

The specifications of the 12/10 FRPM machine are shown in Table 1. On the other hand, a crosssectional of the understudying machine is depicted in Figure 1. It can be seen that the FRPM machine is construed with salient pole rotor made of iron, while both windings and the PMs are located on the stator. Each stator tooth has two PMs with opposite polarity. It should be noted that the windings are concentrated windings, which are more preferable, since they lead to less copper usage resulting in copper loss reduction, and machine efficiency improvement.

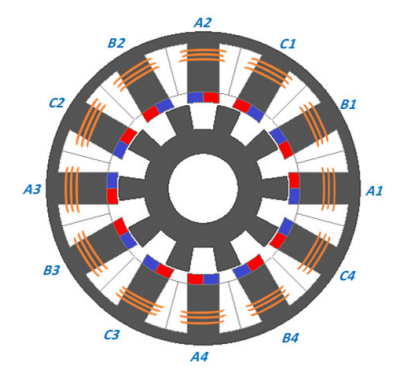

Table 1. Design parameters

\begin{tabular}{cc}
\hline Parameters & Values \\
\hline Stator pole number & 12 \\
Rotor pole number & 10 \\
Air-gap length $(\mathrm{mm})$ & 0.5 \\
Outer radius of stator $(\mathrm{mm})$ & 45 \\
Inner radius of stator $(\mathrm{mm})$ & 27.75 \\
Shaft radius $(\mathrm{mm})$ & 10 \\
Z-direction length $(\mathrm{mm})$ & 50 \\
Speed $(\mathrm{rpm})$ & 500 \\
PM thickness $(\mathrm{mm})$ & 3 \\
\hline
\end{tabular}

Figure 1. FRPM machine configuration

\section{PERFORMANCES COMPARISON}

\subsection{No-load}

No-load performances of the 12/10 FRPM machine are compared at three operating conditions, centricity, static eccentricity and dynamic eccentricity. Figure 2 shows three-phase flux linkage waveforms for the machine under healthy (centric) as well as static and dynamic eccentrics conditions, when the rotor rotates 360 electrical degrees. Notably, the centric machine delivers balanced three-phase flux linkage waveforms. In contrast, both static and dynamic eccentric machines have unequal fundamental values for their flux linkage, because of the irregular air gap, which is caused by the rotor eccentricity. Hence, the phases, which have coils facing the narrow air gap shows higher flux linkage compare to these having

The effect of static and dynamic eccentricities on the performance of flux ... (Ahlam Luaibi Shuraiji) 
coils facing the wide air gap. It must be mentioned that the differences between the fundamental values are small and can be neglected. This is because the understudying machine size is small and has a small air gap $(0.5 \mathrm{~mm})$. Furthermore, three-phase back-EMF of the three operating conditions are illustrated in Figure 3. As consequences of balanced and unbalanced flux linkage waveforms the healthy and eccentric machines show balanced and unbalanced three-phase back-EMF waveforms, respectively. Moreovere, the predicted cogging torque waveforms and the FFT for the machine with three operating conditions are compared in Figure 4. Obviously, the centric and eccentric machines have the same fundamental harmonic (6th harmonic). low order harmonics (1st, 2nd and 5th) are presented in both static and dynamic eccentric conditions, while they are not excited for centric condition. The centric machine exhibits symmetrical cogging torque, however both static and dynamic eccentric machines have asymmetrical cogging torque.

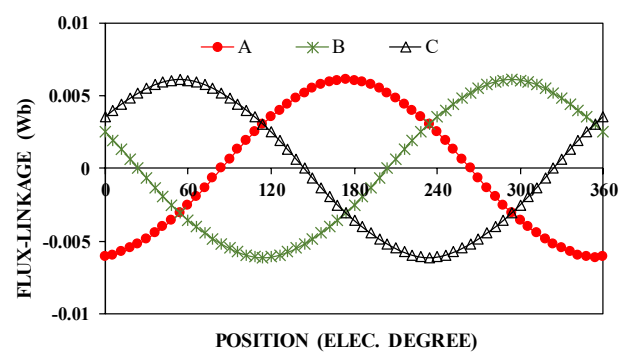

(a)

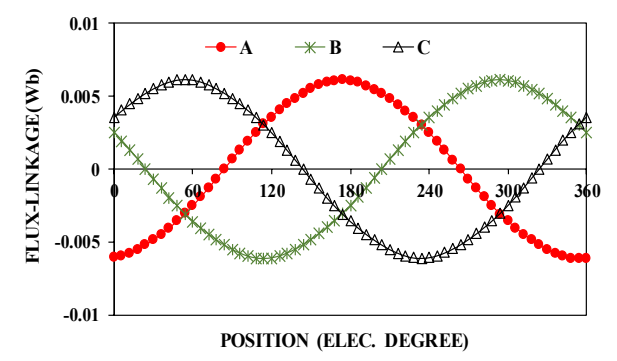

(c)

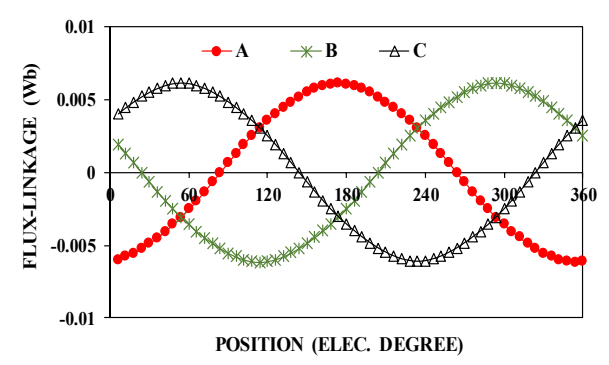

(e)

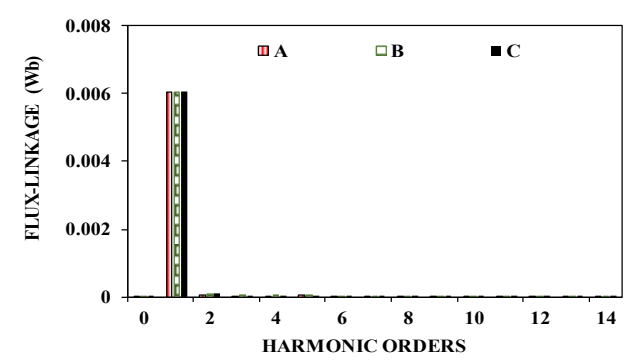

(b)

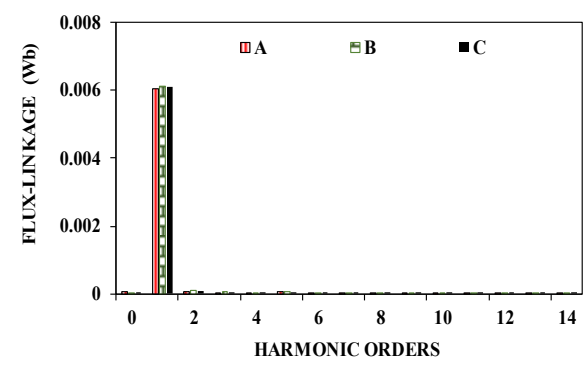

(d)

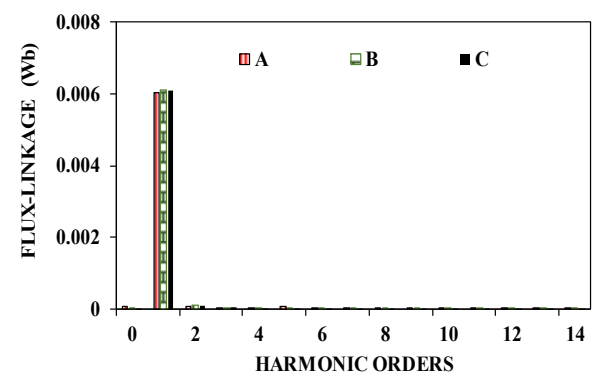

(f)

Figure 2. Flux linkage for three operating conditions, (a) Waveform healthy condition. (b) FFT healthy condition, (c) Waveform static eccentricity, (d) FFT static eccentricity, (e) Waveform dynamic eccentricity,

(f) FFT dynamic eccentricity 


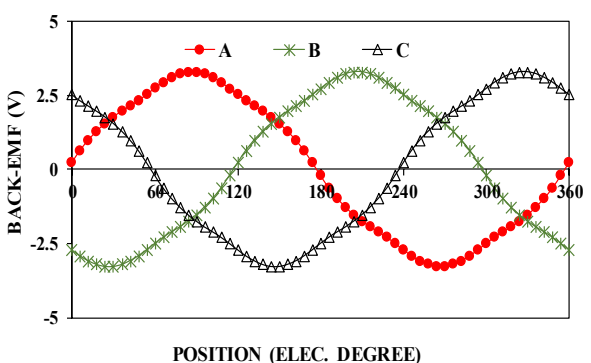

(a)

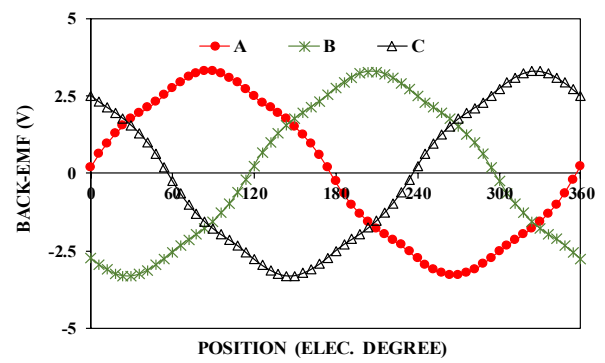

(c)

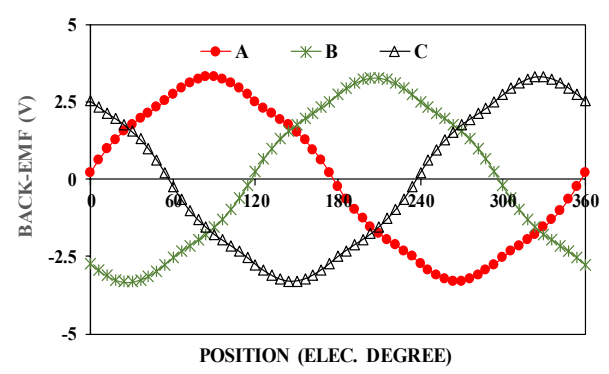

(e)

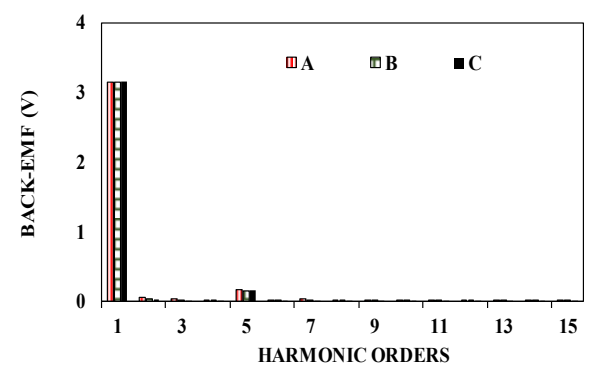

(b)

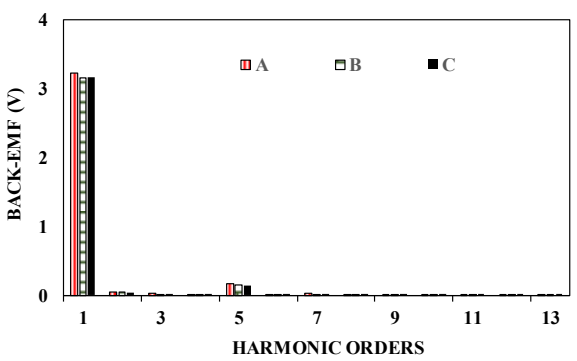

(d)

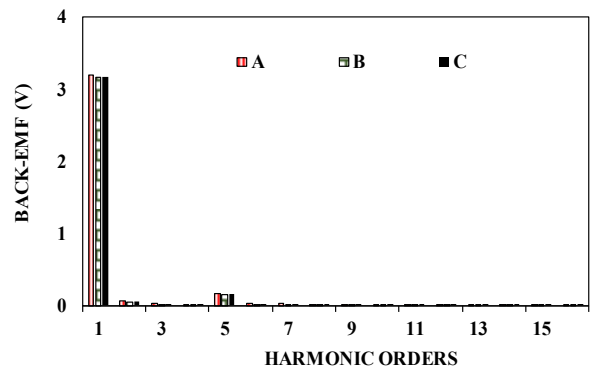

(f)

Figure 3. Back-EMF for three operating conditions, (a) Waveform healthy condition, (b) FFT healthy condition, (c) Waveform static eccentricity, (d) FFT static eccentricity, (e) Waveform dynamic eccentricity, (f) FFT dynamic eccentricity

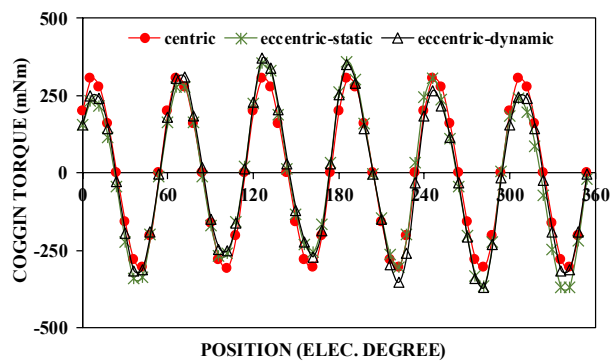

(a)

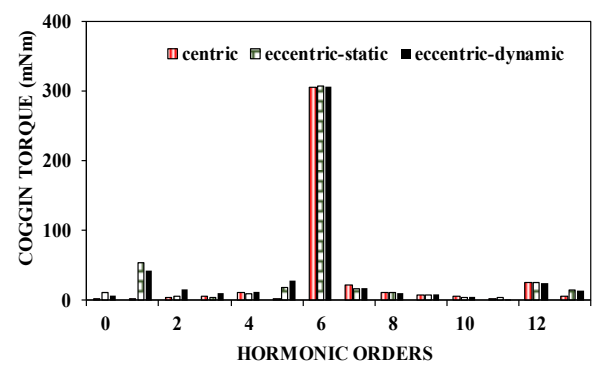

(b)

Figure 4. Cogging torque comparison, (a) Waveform, (b) FFT 


\subsection{On-load}

Electromagnetic torque waveforms of the FRPM machine with three operating conditions are compared in Figure 5. Moreover, torque ripple for the machine with the mentioned operating conditions are illustrated in Figure 6. Although the machines have the same average electromagnetic torque for the three operating conditions, the centric machine shows the lowest torque ripple followed by dynamic eccentric and the static eccentric machine has the highest torque ripple.

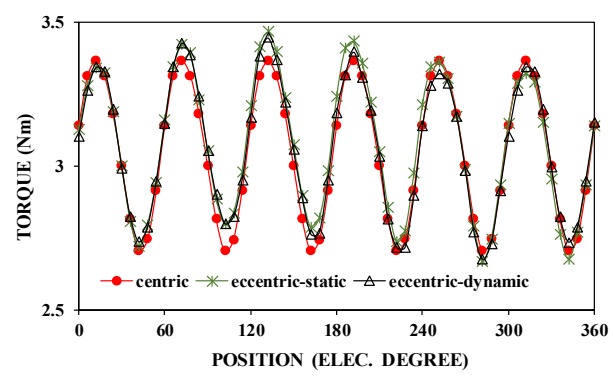

Figure 5. Torque comparison

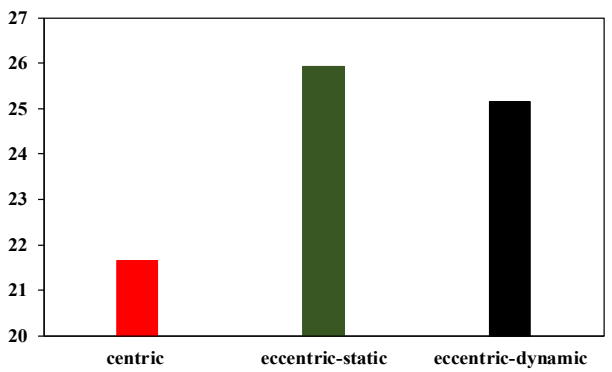

Figure 6. Torque ripple comparison

\subsection{Unbalanced magnetic force}

Usually, for the electrical machines, the electromagnetic force consists of radial and circumference components. These components can be calculated based on the Maxwell stress method [25].

$$
\begin{aligned}
& F_{r}=\frac{1}{2 * \mu_{\circ}}\left(B_{r}^{2}-B_{t}^{2}\right) \\
& F_{t}=\frac{1}{\mu_{\circ}}\left(B_{r} * B_{t}\right)
\end{aligned}
$$

where $F_{r}$ and $F_{t}$ are the radial and circumference components of the electromagnetic force, while $B_{r}$ and $B_{t}$ represent the radial and circumference components of the air-gap flux density. Moreover, $\mu_{\circ}$ is the air permeability. In the rotary permanent magnet machines, the electromagnetic torque is contributed by the circumference force, when the stator windings are excited. In contrast, the radial force has no contribution to the electromagnetic toque, however, it leads to unbalanced magnetic force that causes vibration and noise. The summation of the radial force for the ideal centric PM machines with even rotor pole is zero, however the existing of the eccentricity in these machines makes the summation of such force to be unbalanced. In this section the unbalanced magnetic force for the machine with three operating conditions for both no-load and load will be predicted by 2D-FEA. The predicted unbalanced magnetic force for one electrical cycle at centric, static and dynamic eccentricity conditions for no-load and load conditions are compared in Figures 78 , respectively. Obviously, the exciting of eccentric results in unbalanced magnetic force with average of about $96 \mathrm{~N}$ and $98 \mathrm{~N}$ for no-load and load, respectively. The centric machine has no unbalanced magnetic force at no-load as well as load operating. On the other hand, the values of unbalanced magnetic force with the eccentric-distance for both machines under the mentioned conditions are listed in Table 2. Clearly, it can be seen that the unbalanced magnetic force increases as the eccentric-distance. Both static and dynamic eccentrics machines have the same values of the unbalanced magnetic force at low value of the eccentric distance. However, at high value of such feature the static eccentric machine shows slightly higher unbalanced magnetic value compared to the dynamic counterpart. It is worth mentioning that the eccentric distance is defined by (3)

$$
e d=\frac{\Delta c}{l g}
$$

where $e d$ is the eccentric-distance, $\Delta c$ represents the displacement between the rotor center to the stator center and $l g$ air-gap length.

Int J Pow Elec \& Dri Syst, Vol. 11, No. 2, June 2020 : $634-640$ 


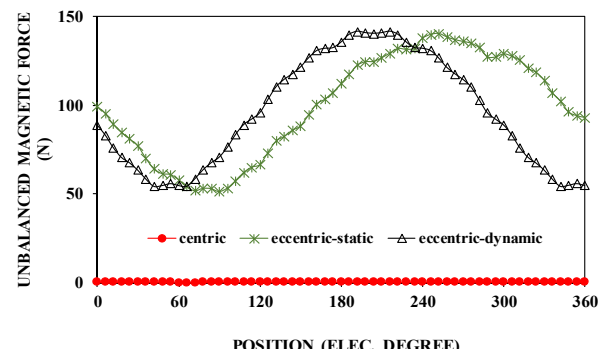

Figure7. Comparison of unbalanced magnetic force for three operating conditions at no-load

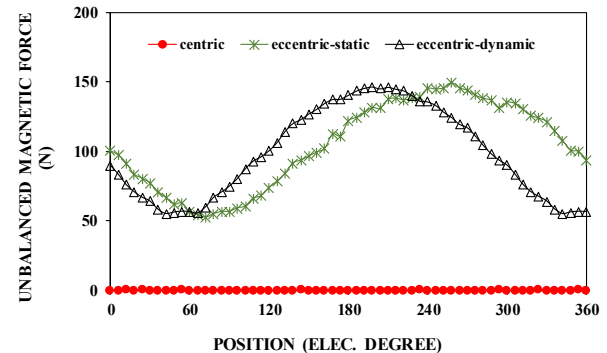

Figure 8. Comparison of unbalanced magnetic force for three operating conditions at load

Table 2. Value of unbalanced magnetic force for different eccentric-distance for both static and dynamic eccentricities (no-load and load operating conditions)

\begin{tabular}{|c|c|c|c|c|}
\hline \multirow[t]{2}{*}{ Eccentric-distance $(\mathrm{mm})$} & \multicolumn{4}{|c|}{ Unbalanced magnetic force $(\mathrm{N})$} \\
\hline & \multicolumn{2}{|c|}{ Static } & \multicolumn{2}{|c|}{ Dynamic } \\
\hline 0 & 0 & 0 & 0 & 0 \\
\hline 0.15 & 73.6 & 78.2 & 70.4 & 72.9 \\
\hline 0.2 & 99.3 & 104.1 & 94.9 & 97.7 \\
\hline 0.25 & 125.5 & 132.9 & 119.8 & 123.8 \\
\hline 0.4 & 210.9 & 223.7 & 201.5 & 206.3 \\
\hline
\end{tabular}

\section{CONCLUSION}

The influence of the eccentricity on the performance of 12/10 FRPM machine has been comprehensively investigated using 2D-FEA. Both eccentricity types are considered. A comparison of three operating conditions for the mentioned machine has been carried out. It has been shown that existing of static or dynamic eccentricities will similarly effect the performance of the understudying machine. Unbalanced 3 phase flux linkage and back-EMF waveforms, low harmonic orders existing of cogging torque and about $16 \%$ higher torque ripple for both static and dynamic eccentric machines compared to the healthy machine. In addition, the value of the unbalanced magnetic force increases with the increasing of the eccentric distance.

\section{REFERENCES}

[1] W.H. Tai, M.C Tsai, Z.L Gaing, P.W Huang, and Y.S Hsu, "Novel stator design of double salient permanent magnet motor," IEEE Trans. on Magnetics, Vol. 50, No. 4, April 2014.

[2] H. Mingjie and X. Wei, "Novel single phase doubly salient permanent magnet machine with asymmetric stator poles," IEEE Trans. on Magnetics, Vol. 53, No. 6, pp. 1-5, June 2017.

[3] X. Zhu, W. Hua, M. Cheng and G. Zhang, "An improved configuration for cogging torque reduction in fluxreversal permanent magnet machines," 2016 IEEE Conference on Electromagnetic Field Computation (CEFC), Miami, FL, 2016.

[4] Laskaris and A. G. Kladas, "Internal Permanent Magnet Motor Design for Electric Vehicle Drive," IEEE Trans. on Industrial Electronics, Vol. 57, No. 1, pp. 138-145, Jan. 2010.

[5] Y. Li, H. Yang, H. Lin and H. Zheng, "Comparative Study of Advanced Stator Interior Permanent Magnet Machines," 2019 IEEE International Electric Machines \& Drives Conference (IEMDC), San Diego, CA, USA, pp. 266-272, 2019.

[6] S. E. Rauch and L. J. Johnson, "Design principles of flux-switching alternators," in AIEE Trans., Vol. 74, No. 3, pp. 1261-1268, January, 1955.

[7] X. Liu, D. Wu, Z. Q. Zhu, A. Pride, R.P Deodhar, and T. Sasaki, "Efficiency improvement of switched flux PM memory machine over interior PM machine for EV/HEV Applications," IEEE Trans. on magnetics, Vol. 50, No. 11, Nov 2014

[8] H. Y. Li and Z. Q. Zhu, "Analysis of flux reversal permanent magnet machines with different consequent pole PM topologies," IEEE Trans. on Magnetics, Vol. 54, No. 11, Nov 2018.

[9] K. Xie, D. Li, R. Qu, Y. Gao and Y. Pan, "A novel flux reversal PM Machine with Halbach array magnets in stator slot opening," 20th International Conference on Electrical Machines and Systems (ICEMS), Sydney, NSW, pp. 1-6, 2017.

The effect of static and dynamic eccentricities on the performance offlux ... (Ahlam Luaibi Shuraiji) 
[10] Z. Z. Wu, Z. Q. Zhu and H. L. Zhan, "Comparative Analysis of Partitioned Stator Flux Reversal PM Machines Having Fractional-Slot Nonoverlapping and Integer-Slot Overlapping Windings," IEEE Trans. on Energy Conversion, Vol. 31, No. 2, pp. 776-788, June 2016.

[11] R. P. Deodhar, S. Andersson, I. Boldea and T. J. E. Miller, "The flux-reversal machine: a new brushless doublysalient permanent-magnet machine," IEEE Trans. on Industry Applications, Vol. 33, No. 4, pp. 925-934, JulyAugust, 1997.

[12] C. Wang, S. A. Nasar and I. Boldea, "Three-phase flux reversal machine (FRM)," IEE Proceedings - Electric Power Applications, Vol. 146, No. 2, pp. 139-146, March, 1999.

[13] C. X. Wang, I. Boldea and S. A. Nasar, "Characterization of three phase flux reversal machines as an automotive generator," IEEE Trans. on Energy Conversion, Vol. 16, No. 1, pp. 74-80, March, 2001.

[14] T. Heoung Kim, S. H. Won, K. Bong and J. Lee, "Reduction in cogging torque in flux reversal machine by rotor teeth pairing" IEEE Trans. on Magnetics, Vol. 41, No. 10, pp 3964-3966, October, 2005.

[15] T. Heoung Kim and J. Lee "A study of the design for the flux reversal machine," IEEE Trans. on Magnetics, Vol. 40, No. 4, pp. 2053-2055, July, 2004.

[16] TH. Kim, "A study on the design of an inset permanent magnet type flux reversal machine," IEEE Trans. on Magnetics, Vol. 45, No. 6, pp. 2859-2862, June, 2009.

[17] J. zhang, M. Cheng, W. Hua and X. Zhu, "New approach to power equation for comparison of doubly salient electrical machines," in Proc. IEEE Industry Applications Annul meeting, pp. 1178-1185, 2006.

[18] D. S. More and B. G. Fernandes, "Power density improvement of three phase flux reversal machine with distributed winding," IET Electric Power Applications, Vol. 4, No. 2, pp. 109-120, February, 2010.

[19] D. S. More, H. Kalluru and B. G. Fernandes, "d-q equivalent circuit representation of three-phase flux reversal machine with full pitch winding," in Proc. IEEE Power Electronics Specialists Conference, Rhodes, pp. 12081214, 2008.

[20] M. H. Remlan, R. Aziz and S. Salimin,” Comparison of different magnet arrangement on performance of flux reversal permanent magnet (FRPM) machine," International Journal of Power Electronics and Drive System (IJPEDS), Vol. 10, No. 3, pp. 1207-1214, September, 2019.

[21] J. Y. Song, K. J. Kang, C. H. Kang and G. H. Jang, "Cogging torque and unbalanced magnetic pull due to simultaneous existence of dynamic and static eccentricities and uneven magnetization in permanent magnet motors," IEEE Trans. on Magnetics, Vol. 53, No. 3, pp. 1-9, March 2017.

[22] H. Mahmoud, N. Bianchi, M. Degano, M. Al-Ani and C. Gerada, "Eccentric Reluctance and Permanent Magnet Synchronous Machines Comparison," IEEE Trans. on Industry Applications, Vol. 54, No. 6, pp. 5760-5771, Nov.Dec. 2018.

[23] J. Hong, S. B. Lee, C. Kral and A. Haumer, "Detection of airgap eccentricity for permanent magnet synchronous motors based on the d-axis inductance," 8th IEEE Symposium on Diagnostics for Electrical Machines, Power Electronics \& Drives, pp. 378-384, Bologna, 2011.

[24] Y. Li, Z. Zhu, G. Li and D. Wu, "Analytical synthesis of air-gap field in permanent magnet machines with rotor eccentricity by superposition method," 2015 IEEE International Magnetics Conference (INTERMAG), Beijing, 2015.

[25] Z. Q. Zhu, Z. P. Xia, L. J. Wu, and G. W. Jewell, “Analytical modeling and finite-element computation of radial vibration force in fractional-slot permanent-magnet brushless machines," IEEE Trans. Industry Applications, Vol. 46, no. 5, pp. 1908-1918, September/October, 2010.

\section{BIBLIOGRAPHY OF AUTHOR}

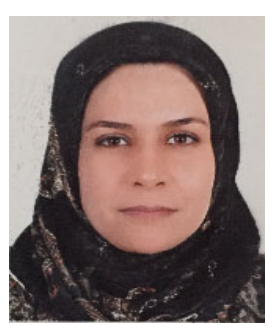

Ahlam Luaibi Shuraiji received the B.Eng. and M.Sc. degrees in Engineering Educational Technology/ Electrical Engineering, from University of Technology, Baghdad, Iraq, in 1998 and 2004, respectively, and the Ph.D. degree in electrical engineering from The University of Sheffield, Sheffield, U.K., in 2017. She is currently a lecturer at the University of Technology/ Electromechanical Engineering department. Her research interests include the design of permanent-magnet machines 